\title{
Comparing virtual consults to traditional consults using an electronic health record: an observational case-control study
}

Ted E Palen ${ }^{1 *+}$, David Price ${ }^{2 \dagger}$, Susan Shetterly ${ }^{3+}$ and Kristin B Wallace ${ }^{4}$

\begin{abstract}
Background: Patients have typically received health care through face-to-face encounters. However, expansion of electronic communication and electronic health records (EHRs) provide alternative means for patient and physicians to interact. Electronic consultations may complement regular healthcare by providing "better, faster, cheaper" processes for diagnosing, treating, and monitoring health conditions. Virtual consultation between physicians may provide a method of streamlining care, potentially saving patients the time and expense of added visits. The purpose of this study was to compare physician usage and patient satisfaction with virtual consultations (VCs) with traditional consultations (TCS) facilitated within an EHR.

Methods: We conducted an observational case-control survey study within Kaiser Permanente, Colorado. A sample of patients who had VCs requested by physicians $(N=270)$ were matched with patients who had TCs requested by physicians ( $N=270)$, by patient age, gender, reason for the consult, and specialty department. These patients (VC and TC), were invited to participate in a satisfaction survey. In addition, 205 primary care physicians who submitted a VC or TC were surveyed.
\end{abstract}

Results: During the study period, 58,146 VC or TC were requested (TC $=96.3 \%)$. Patients who completed a satisfaction survey (267 out of 540 patients, 49.4\% response rate) indicated they were satisfied with their care, irrespective of the kind of consult (mean 10-point Likert score of 8.5). 88 of 205 primary care physicians surveyed (42.9\%) returned at least one survey; VC and TC survey response rates and consulted departments were comparable $(p=0.13)$. More TCs than VCs requested transfer of patient care $(p=0.03)$, assistance with diagnosis $(p=0.04)$ or initiating treatment $(p=0.04)$. Within 3 weeks of the consultation request, $72.1 \%$ of respondents reported receiving information from VCs, compared with $33.9 \%$ of the TCs $(p<0.001)$. Utility of information provided by consultants and satisfaction with consultations did not differ between VCs and TCs.

Conclusions: Referring physicians received information from consultants more quickly from VCs compared with TCs, but the value and application of information from both types of consultations were similar. VCs may decrease the need for face-to-face specialty encounters without a decrease in the patient's perception of care.

Keywords: Consultations, Referrals, Electronic medical record, Value of information, Physician satisfaction, Patient satisfaction

\footnotetext{
* Correspondence: ted.e.palen@kp.org

${ }^{\dagger}$ Equal contributors

'Department of Internal Medicine, Colorado Permanente Medical Group,

Institute for Health Research, Kaiser Permanente, Denver, CO, USA

Full list of author information is available at the end of the article
} 


\section{Background}

Traditionally, patients receive health care primarily by face-to-face encounters. Some authors suggest that $25 \%$ to $70 \%$ of all patients seeking care do not need a face-to-face appointment with a physician [1,2]. "Virtual medicine" using telecommunication and computerized means is being studied in various venues in efforts to provide coordinated care [3-5]. Virtual outreach may reduce the need for face-to-face appointments, reduce unneeded contacts with the health care system, increase patient satisfaction and improve patient health status. Secure, internet-based consultations may complement regular healthcare by providing "better, faster, cheaper" processes for diagnosing, treating, and monitoring health conditions [6-8]. Virtual consults may allow clinicians to receive guidance without added patient cost and inconvenience of physically going to the specialist, and may improve access to subspecialists by "freeing up" some appointments for use by other patients needing in-person visits (unpublished, Price DW, 2009). Physicians have on average up to two questions about patient care per patient encounter [9-12], but search for answers less than half the time $[9,10,12,13]$, with only a $50-75 \%$ success rate in finding answers [10,12,14-18]. Electronic "virtual" consultations may help clinicians obtain answers. However, even with increasing availability of electronic communication, less than $5 \%$ of consultations occur by email [14]. In at least one study, electronic communication between family medicine physicians and specialists was described as an efficient tool [19]. Electronic communication and increasing use of electronic health records (EHRs) make virtual consultation between physicians a promising method of streamlining care, potentially saving patients the time and expense of added visits. Younger generations of patients, who increasingly use electronic communication and social networking may come to expect virtual models of healthcare [20].

Shershneva and colleagues described a model of how physicians learn from specialty consultations [21]. Earlier pilot work [22] suggests that answers obtained from consultations have the potential to affect care that physicians provide for subsequent patients. Other than this work, to our knowledge, the extent to which information provided during physician-to-physician consultation is used in the care of the index patient or subsequent patients has not been well described. A few studies have investigated virtual consultation using the electronic messaging capabilities of an EHR system within an integrated healthcare environment [23-25]. Researchers have evaluated the use of telemedicine for remote consultations [26-29]. A recent meta-analysis showed a consistent pattern of improved primary care-specialist collaboration when interactive communication methods were employed [30]. A recent demonstration project showed how the use of an EHR has the potential to improve coordination of care between members of a patient's care team but using an EHR to facilitate interoffice communication is still a barrier [31]. Detailed descriptions are lacking which examine the use of an EHR with an embedded secure messaging system between primary care and specialty care physicians in the context of an integrated health care delivery system.

We conducted an observational study comparing primary care referring physician perceptions on the value of virtual consultations (VCs) compared to traditional consultations (TCs). We quantified and classified the types of VCs and TCs requested, by whom, and for what purpose. We also surveyed patients who had either type of consult to gauge their impression of the care they received. We hypothesized that there would be no difference in physician satisfaction with the consultation process, the immediate clinical utility of the information from the consultant, the use of received information in subsequent patients, and overall satisfaction with the consultation by the physician or by the patient. We also hypothesized that referring physicians would receive information from a $\mathrm{VC}$ sooner than from a TC.

\section{Methods}

\section{Study setting, design, and population}

Kaiser Permanente Colorado (KPCO), a large group model integrated delivery system, provides healthcare for a diverse population of over 500,000 members in the Denver-Boulder-Longmont, Colorado metropolitan area. The KPCO institutional review board approved this study. KPCO has used a fully integrated EHR within KPCO since 1997; using KP HealthConnect EHR (KP HealthConnect ${ }^{\mathrm{TM}} \mathrm{KPHC}$, Epic Systems, Verona, Wisconsin) since 2004. The EHR includes all clinically relevant progress notes, telephone and email patient encounters along with an integrated computer provider order entry (CPOE) for all laboratory tests, imaging tests, medications and referrals. When a specialty department receives an electronic request for a traditional consultation, a staff member contacts the patient or the patient contacts the department for scheduling an appointment.

Clinicians may, in the course of their normal workflow within the EHR, use the CPOE function to submit an "advice only" consultation, for questions about etiology of a condition, diagnostic evaluation, treatment recommendations, or other questions about a particular patient. A specialist in the department reviews the advice request, which is attached to the patient's electronic chart, facilitating easy review of the patient's medical information. The specialist enters their recommendations into the consult request and returns the message to the requesting clinician's electronic in-basket for review, usually within 24 hours. 
During the study period, June 1, 2008 to Nov 22, 2008, we identified all adult ( $\geq 18$ years of age) patient encounters in the EHR database which contained a VC or a $\mathrm{TC}$ to a specialty care department excluding requests for behavioral health consultation to maintain strict patient confidentiality. Self-referrals, durable medical equipment orders, and radiology orders were also excluded as these are not part of the advice messaging system. We reviewed $\mathrm{VC}$ and $\mathrm{TC}$ requesting patterns and only retained referral departments with evidence in the EHR of both types of consults $(\mathrm{N}=33,390)$.

We randomly selected $270 \mathrm{VC}$ and matched them to 270 similar TC that occurred in the same week. Consults were matched by patient age $( \pm 10$ years), patient gender, specialty of consultation and the reason (3 digit ICD-9 code) for the consult. Selection and matching occurred every two weeks and selected patients were invited to participate in a telephone survey. Patients were contacted by phone within 2-4 weeks after the visit that contained the consultation request, and after obtaining informed consent (Additional file 1); we administered a survey assessing satisfaction with the clinical encounter and follow-up care related to the visit that included the consultation request. We adapted the survey from the modified Adult Ambulatory Care Consumer Assessment of Health Plans Survey (A-CAHPS) [32]. Survey questions (Additional file 2) assessed the specific visit in which the consultation was requested.

The referring physician for each selected TC and VC were invited by email to participate in an on-line survey (Additional file 3) about reasons for consultation (using a checklist based on previous pilot work [22] and modified from Ely's taxonomy of clinical questions) [33], answers received, if answers met immediate patient care needs, likely or actual use of the information in subsequent patient care, impact of the consult process on physician work flow, and overall satisfaction with the consult. To avoid burdening physicians, a maximum of one survey per physician was sent each month, eliminating 115 consultations. Four consultations came from physicians who we were unavailable to survey. The final number of surveys sent to physicians was 421 (211 TC and $210 \mathrm{VC}$ ).

\section{Statistical methods}

We calculated descriptive statistics and two-group comparisons between VCs and TCs. Although matching was used to select comparable VCs and TCs, survey selection as described above and physician non-response limited the number of matched pairs in the final survey sample, so that matched analytic methods were not used. Unmatched analyses of studies that match on exposure, rather than outcome, are generally less problematic since results will be accurate unless differential loss to follow- up introduces distortions. [34] The matching effort was successful in producing frequency matched comparison groups that did not differ on age or gender and restricted the sample to consult reason codes that were used for both TCs and VCs during the study time period. Differences between responding and nonresponding physicians in use of TCs and VCs were evaluated using t-tests for mean consultation rates, Wilcoxon rank-sum tests for median consult rates, and Poisson regression models for ratios of VC to TCs. For variables measured at the patient level, p-values for differences between VCs and TCs were estimated using generalized linear mixed models that included a random effect for physicians (linear and logistic models estimated using SAS MIXED and GLIMMIX). SAS version 9.2 (Cary, N.C.) was used for all analyses.

\section{Results}

\section{Comparison of virtual to traditional consults}

We identified 77,163 referrals for consultation orders of all types originating from all sources (see Figure 1). The majority $(\mathrm{N}=58,146,75.4 \%)$ were for either $\mathrm{VC}$ or $\mathrm{TC}$ consultations for 44,034 unique adult patients. Physicians initiated the majority $(47,144 / 58,146,81.1 \%)$ of consultation requests. We focused our analysis on internal medicine and family medicine physicians, since they are the primary health care providers who coordinate care for their panel of patients and the primary users of the specialist's advice. These physicians submitted 22,391 consultation requests for 19,441 unique adult patients; most of these were for TCs $(20,825 / 22,391$, $93.0 \%)$. Both types of consult requests occurred primarily for female patients $(13,317 / 22,391,59.5 \%)$.

The most common specialty departments for TCs were Physical Therapy (5,871/20,825, 28.2\%), Orthopedics $(2,641 / 20,285,12.7 \%)$, Cardiology $(2,129 / 20,825$, $10.2 \%)$, Dermatology $(2,079 / 20,285,10.0 \%)$ and General Surgery $(1,841 / 20,285,8.8 \%)$. The most common specialty departments for VCs included Dermatology (282/1,566, 18.0\%), Neurosurgery (211/1,566, 13.5\%), Endocrinology (170/1,566, 11.0\%), Neurology (124/1,566, $7.9 \%)$, and Orthopedic Surgery (96/1,566, 6.1\%). Conditions that prompted the need for a consult were present for greater than 3 months in $76 \%$ of patients (203 of 267 patient survey respondents, $94.2 \%$ of the $97 / 103 \mathrm{VC}$ and $75.1 \%$ of the $106 / 140$ TC). One hundred fifty-one (56.6\%) of survey respondent patients had already seen a specialist for the index condition in the last 12 months prior to the VC or TC $(74 / 137,54.0 \%$ with $\mathrm{VC}$ and $77 / 140$, $55.0 \%$ with TC). Only $59.2 \%(160 / 240)$ of the $\mathrm{VCs}$ required conversion to a "face-to-face" specialist visit after the initial VC. This means that about $40 \%$ of physician questions could be handled through the virtual consultation method. 


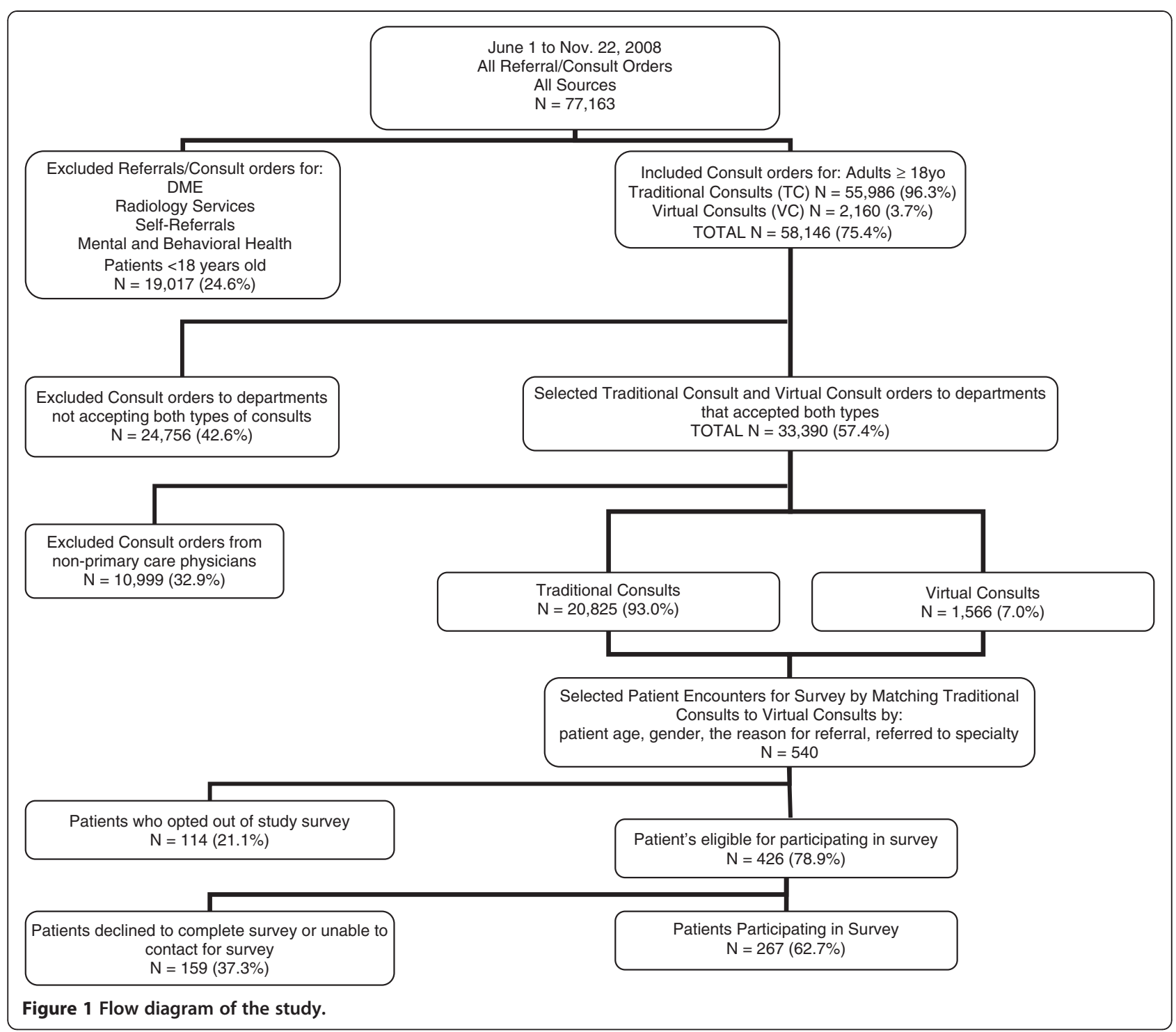

\section{Patient satisfaction survey}

Some patients pro-actively opted out of participating in the survey $(\mathrm{N}=114,21.1 \%)$, some declined to complete the survey once they were called $(\mathrm{N}=43,8.0 \%)$, and we were unable to contact others $(\mathrm{N}=115,21.3 \%)$. The remaining 267 patients completed the survey, for a 49.4\% overall response rate. Response rates were similar among patients who had VCs $(\mathrm{N}=128 ; 47.9 \%)$ compared to TCs $(\mathrm{N}=139 ; 52.1 \% ; \mathrm{p}=0.30)$.

Patients who completed the survey were satisfied with the care they received (mean ratings greater than 8.5 on a 10 point Likert scale) from primary care and specialist physicians, irrespective of the kind of consult (see Table 1).

\section{Physician survey}

Of the 205 physicians surveyed, 88 (42.9\%) replied to at least one survey, with no statistically significant differences between responding and non-responding physicians in the number of TCs and VCs ordered during the study period (Table 2). One hundred twenty-eight of 421 surveys (30.4\%) were returned. Fifty-nine physicians completed one survey, 22 completed two surveys, three completed three surveys, and four completed four surveys. Of surveyed family physicians, $51.6 \%$ responded to at least one survey, compared with $36.5 \%$ of general internal medicine physicians $(\mathrm{p}=0.03)$. Response rates on VCs $(71 / 210 ; 33.8 \%)$ and TCs $(57 / 211 ; 27.0 \%)$ were comparable $(\mathrm{p}=0.13)$. Patients represented in the physician survey responses were mostly female (60.9\%; $\mathrm{p}=0.62$ compared with survey non-responses), with a mean age of $53.7 \pm 11.8$ years ( $\mathrm{p}=0.88$ compared with survey non-responses). Patients receiving TCs or VCs in the returned survey sample did not differ by age or gender. A majority of physicians $(57.8 \%$ for $\mathrm{VC}$ and $42.1 \%$ for TC) who responded to 
Table 1 Patient survey results of rating of quality of medical care (10 point Likert Scale)

\begin{tabular}{|c|c|c|c|c|c|c|}
\hline & & & & & & Comparisons of VC vs TC \\
\hline & $\mathbf{N}$ & Mean & Median & Min & Max & p value* \\
\hline \multicolumn{7}{|c|}{ Rating of Primary Care Physician } \\
\hline Virtual consult (VC) & 127 & 8.69 & 9 & 0 & 10 & 0.99 \\
\hline Traditional consult (TC) & 138 & 8.69 & 9 & 4 & 10 & \\
\hline \multicolumn{7}{|l|}{ Rating of Medical care } \\
\hline Virtual consult (VC) & 128 & 8.67 & 9 & 0 & 10 & 0.51 \\
\hline Traditional consult (TC) & 139 & 8.55 & 9 & 3 & 10 & \\
\hline \multicolumn{7}{|c|}{ Rating of Specialist Recommendations } \\
\hline Virtual consult (VC) & 41 & 8.71 & 10 & 0 & 10 & 0.63 \\
\hline Traditional consult (TC) & 65 & 8.51 & 9 & 1 & 10 & \\
\hline
\end{tabular}

* $\mathrm{p}$ values linear models with a random effect to adjust for patient clustering within physicians.

Total patient survey respondents, $\mathrm{N}=267$, however not all respondents answered all the questions so respondent numbers vary depending on the survey question.

the survey indicated one reason for placing the consultation (range 1-5 reasons). Figure 2 shows that the reasons for TC and VC were generally similar, with more TCs than VCs intended to transfer care of the patient $(\mathrm{p}=0.03)$, assist with diagnosis $(\mathrm{p}=0.04)$ or start treatment and refer back to primary care $(\mathrm{p}=0.04)$. There were no differences between family and internal medicine physicians in reasons given for $\mathrm{VC}$ compared with TC (data not shown).

Many aspects of initiating VCs and TCs were similar. Few physicians $(7.1 \%)$ called the specialty department before requesting a consultation. Only $2.4 \%$ of respondents indicated that the consultation process disrupted their workflow, with no difference between $\mathrm{VCs}$ and TCs. Physicians did not generally solicit patient

Table 2 Frequency of virtual and traditional consults among surveyed physicians

\begin{tabular}{lccc}
\hline & $\begin{array}{c}\text { Responding } \\
\text { PCPs } \\
\mathbf{n = 8 8}\end{array}$ & $\begin{array}{c}\text { Non- } \\
\text { responding } \\
\text { PCPs } \\
\mathbf{n = 1 1 7}\end{array}$ & $\begin{array}{c}\text { Responding vs } \\
\text { non-responding } \\
\text { PCPs } \\
\text { p-value }\end{array}$ \\
\hline $\begin{array}{l}\text { Virtual Consults (VC) } \\
\text { Range }\end{array}$ & $0-36$ & $0-27$ & \\
Mean (SD) & $7.4(6.6)$ & $6.8(5.9)$ & $0.46^{*}$ \\
Median & 5 & 5 & $0.56^{\dagger}$ \\
Traditional Consults (TC) & & \\
Range & $5-203$ & $12-231$ & $0.31^{*}$ \\
Mean (SD) & $86.6(42.1)$ & $92.5(40.8)$ & $0.47^{\dagger}$ \\
Median & 87 & 89 & $0.19^{*}$ \\
VC/TC (\%) & $11.4 \%$ & $8.0 \%$ & \\
\hline
\end{tabular}

* $\mathrm{p}$ value from $t$-test.

${ }^{\dagger} \mathrm{p}$ value from Wilcoxon rank sum test.

* $\mathrm{p}$ value from poisson regression model for VC counts outcome, with log TC counts as the offset variable.

Model adjusted for over dispersion using scale parameter estimated by the square root of Pearson's chi-square/degrees of freedom.

421 physician surveys sent to 214 physicians who ordered a TC and 207 to physicians who ordered a VC. preference for type of consultation, but more did so before TCs (41.2\%) than VCs (26.5\%), a difference that nearly reached significance $(p=0.15)$. Physicians reported that only $22.5 \%$ of patients volunteered a preference for one type of consultation, with no differences between TCs and VCs (Table 3). Within 3 weeks of the consultation request, $72.1 \%$ of respondents reported receiving information from the VC, compared with 33.9\% of the TCs $(\mathrm{p}=<0.001)$, (Table 3$)$. Requesting physicians did not differ in their satisfaction with the information provided or perception of the utility of TCs compared with VCs.

Sixty-eight (53.1\%) of 128 physicians surveyed provided answers to the question on the use of the information provided (this question could not be answered by physicians who had not yet received consultation information) (Table 4). Three-quarters of respondents indicated that all of the information provided was used in the care of the index patient; $7.4 \%$ reported using none of the information (TC vs. VC p = 0.75). Sixteen $(23.5 \%)$ stated that they used index consultation information in the care of subsequent patients ( $\mathrm{TC}$ vs. $\mathrm{VC} \mathrm{p}=0.78$ ). Of the remaining 52 physicians, 18 indicated that they were at least somewhat likely ( 6 or higher on a 10 point Likert scale) to use the information from the index consultation in subsequent patient care ( 21 of the 52 physicians did not answer this question). There were no statistically significant differences (by specialty or number of surveys sent) between physicians who rated usefulness of or satisfaction with information from the consultation compared with those who did not answer these questions (data not shown).

\section{Discussion}

Little is known about the use of virtual consultations in an electronic health record. Our study demonstrated that using virtual consults via secure messaging within 


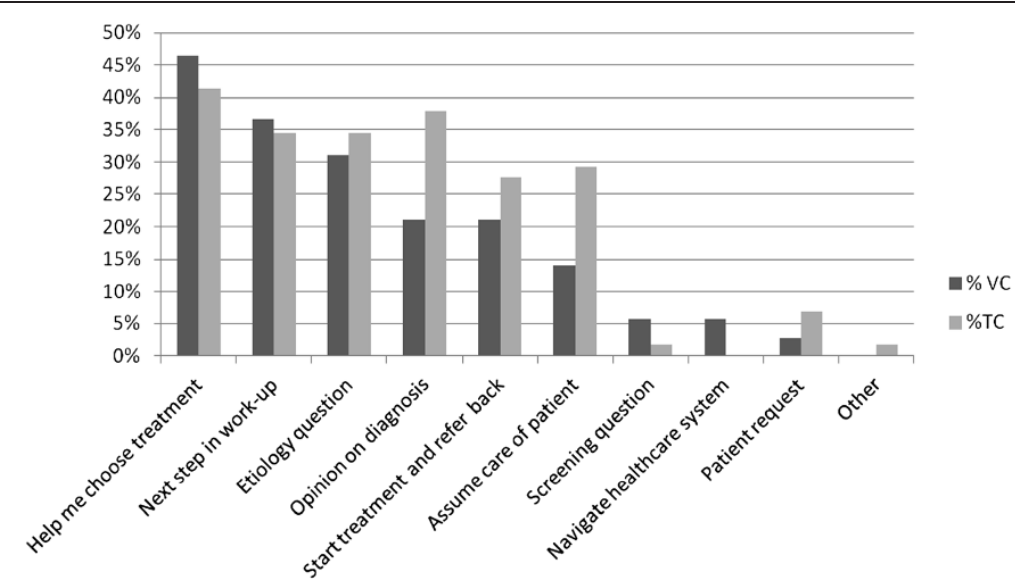

Figure 2 Reasons given by requesting physicians for virtual and traditional consultation. VC, Virtual consult; TC, Traditional consult. ${ }^{*} p<0.05$.

an EHR did not adversely affect patient's perceived satisfaction with their care. While less than $7 \%$ of all the consults were virtual during the study time, when a provider opted to use a virtual consult to ask a question regarding patient care, $40 \%$ of the time a face-to-face consultation with the specialist was not needed. As providers (both primary care and specialists) and our patients gain more experience with this type of consultation, if the rate of virtual consults increases, we may experience improved access to specialists for patients who do require a faceto-face consultation. Patient satisfaction with care may increase if their questions are addressed by specialists

Table 3 Referring physician's comments on the consultation requesting process, timeliness, utility, and satisfaction of information received from consultations

\begin{tabular}{|c|c|c|c|c|c|}
\hline Survey question & $\begin{array}{c}\text { All consultations } \\
\text { number/respondents } \\
(\%)\end{array}$ & $\begin{array}{l}\text { VC number/respondents } \\
\text { (\%) } 71 \text { total } \\
\text { responses possible }\end{array}$ & $\begin{array}{l}\text { TC number/ } \\
\text { respondents } \\
(\%) 58 \text { total } \\
\text { responsespossible }\end{array}$ & $\begin{array}{l}P \text {-value } \\
\text { for } \\
\text { VC vs. TC }\end{array}$ & $\begin{array}{c}\text { number of missing } \\
\text { or cannot } \\
\text { recall responses } \\
\text { ( } n=128 \text { maximum) }\end{array}$ \\
\hline $\begin{array}{l}\text { Referring physician called department } \\
\text { before making consultation? }\end{array}$ & 9/127 (7.1\%) & 4/70 (5.7\%) & 5/57 (8.8\%) & 0.52 & 1 \\
\hline $\begin{array}{l}\text { Process of making consultation majorly } \\
\text { or fairly disruptive to workflow? }\end{array}$ & $3 / 123$ (2.4\%) & $2 / 67(3.0 \%)$ & $1 / 56(1.8 \%)$ & 0.67 & 5 \\
\hline $\begin{array}{l}\text { Referring physician solicited patient } \\
\text { preference for type of consultation. }\end{array}$ & $41 / 123(33.3 \%)$ & $18 / 68$ (26.5\%) & 23/55 (41.2\%) & 0.15 & 5 \\
\hline $\begin{array}{l}\text { Patients who expressed a preference } \\
\text { for consultation type. }\end{array}$ & $25 / 111(22.5 \%)$ & $16 / 60(26.7)$ & 9/51 (17.6) & 0.38 & 17 \\
\hline $\begin{array}{l}\text { Information received from consultant by } \\
\text { the time referring physician completed } \\
\text { the survey ( } 2-3 \text { weeks after consultation } \\
\text { request) }\end{array}$ & $68 / 124(54.8 \%)$ & 49/68 (72.1\%) & 19/56 (33.9\%) & $<0.001$ & 4 \\
\hline \multicolumn{6}{|c|}{ Of referring physicians $(n=68$ ) who received consultant information at the time of the survey, usefulness with information from consultation } \\
\hline Useful (8-10 on 10 point Likert scale) & 25/33 (75.6\%) & $17 / 21(81.0 \%)$ & $8 / 12(66.7 \%)=$ & 0.66 & 35 \\
\hline $\begin{array}{l}\text { Somewhat useful (6-7 on } 10 \text { point } \\
\text { Likert scale) }\end{array}$ & $4 / 33(12.1 \%)$ & $2 / 21(9.5 \%)$ & $2 / 12(16.7 \%)$ & & \\
\hline Not useful (1-5 on 10 point Likert scale) & $4 / 33(12.1 \%)$ & $2 / 21(9.5 \%)$ & $2 / 12(16.7 \%)$ & & \\
\hline \multicolumn{6}{|c|}{ Of referring physicians ( $n=68$ ) who received consultant information at the time of the survey, satisfaction with information from consultation } \\
\hline Satisfied (8-10 on 10 point Likert scale) & 26/36 (72.2\%) & $18 / 24(75.0 \%)$ & $8 / 12(66.7 \%)$ & 0.40 & 32 \\
\hline $\begin{array}{l}\text { Somewhat satisfied (6-7 on } 10 \text { point } \\
\text { Likert scale) }\end{array}$ & 5/36 (13.9\%) & 2/24 (8.3\%) & $3 / 12$ (25.0\%) & & \\
\hline $\begin{array}{l}\text { Not satisfied ( } 1-5 \text { on } 10 \text { point } \\
\text { Likert scale) }\end{array}$ & $5 / 36(13.9 \%)$ & $4 / 24(16.7 \%)$ & $1 / 12(8.3 \%)$ & & \\
\hline
\end{tabular}

*p values from logistic models with a random effect to adjust for clustering of patients within physicians. 
Table 4 Use of information from consultation in care of index and subsequent patients

\begin{tabular}{|c|c|c|c|c|}
\hline Survey question & $\begin{array}{c}\text { All consultations } \\
\text { number/respondents } \\
(\%)\end{array}$ & $\begin{array}{c}\text { VC number/respondents } \\
(\%)\end{array}$ & $\begin{array}{c}\text { TC number/respondents } \\
(\%)\end{array}$ & $\begin{array}{l}\text { P value* } \\
\text { VC vs. TC }\end{array}$ \\
\hline \multicolumn{5}{|c|}{ Use of information from the specialist to care for the index patient } \\
\hline All & $51 / 68(75.0 \%)$ & $38 / 49(77.6 \%)$ & $13 / 19(68.4 \%)$ & 0.75 \\
\hline Some & 12/68 (17.7\%) & $8 / 49(16.3 \%)$ & $4 / 19(21.1 \%)$ & \\
\hline None & $5 / 68(7.4 \%)$ & $3 / 49(6.1 \%)$ & $2 / 19(10.5 \%)$ & \\
\hline $\begin{array}{l}\text { Already used information from index } \\
\text { consultation in care of other patients? }\end{array}$ & 16/68 (23.5\%) & $12 / 49(24.5 \%)$ & $4 / 19(21.1 \%)$ & 0.78 \\
\hline \multicolumn{5}{|l|}{ If no, likely to use information in the future? } \\
\hline Somewhat - very likely (6-10 on 10 point Likert scale) & $18 / 52(34.6 \%)$ & $14 / 37(37.8 \%)$ & $4 / 15(26.7 \%)$ & 0.15 \\
\hline Not very - not likely (1-5 on 10 point Likert scale) & $13 / 52(25.0 \%)$ & $6 / 37(18.9 \%)$ & $7 / 15(46.7 \%)$ & \\
\hline Did not answer question & $21 / 52(40.4 \%)$ & $17 / 37(43.2 \%)$ & 5/15 & \\
\hline
\end{tabular}

* $p$ values from logistic models with a random effect to adjust for clustering of patients within physicians.

421 physician surveys sent to 214 physicians who ordered a TC and 207 to physicians who ordered a VC.

without the burden of additional office visits. We do not know the optimal proportion between VC and TCs. With increasing experience, providers may learn which conditions do not need TCs and can be addressed with VCs. By incorporating this knowledge into caring for their other patients, they may improve the efficiency and quality of care they provide for their entire patient population.

The vast majority of study physicians relied on TCs, perhaps out of habit, comfort with traditional means of consultation, or slow adaptation of a new workflow. They seemed to somewhat selectively apply VCs, specifically by opting for TCs for confirmation of diagnosis, initiating a new treatment, or assuming care of the patient. We found that physicians received information from consultants more quickly using VCs than TCs. Otherwise, physicians utilized VCs and TCs for similar types of clinical questions and conditions. Most information from both TCs and VCs was used in care of index patients; many physicians had already or planned to use information from the consultation in the care of subsequent patients. TCs and VCs were minimally disruptive to physician workflow, and there were no differences in referring physician satisfaction between the two types of consultations. Most physicians did not determine patient preference for consult type, and physicians reported that most patients did not volunteer a preference for type of consultation.

Also, most patients did not express a preference for type of consult ordered, perhaps due to being unaware of the option of a VC (for those patients receiving traditional consultation), trusting their physician to determine the most appropriate type of consult, previous experience with consultation, lack of incentive to choose one form of consult over another, or truly having no preference.

Our results suggest that information from consultations is often applied not only in the care of the index patient, but also in caring for subsequent patients. Future application of new knowledge learned from a patient encounter is a desirable outcome of "point of care" learning; helping physicians document, process, and reflect on knowledge learned through practice-based consultation is a potential area for future outcomes-focused continuing medical education (CME) efforts [35]. Planning to use this information in the care of subsequent patients can be considered a type of commitment to change statement; these statements have been shown to be a reasonable predictor of future practice change [36-38].

\section{Limitations}

Our study was conducted in a large group model practice with experience using a shared EHR, where all physicians are paid on salary, not on a relative value unit production system. This is an ideal setting for demonstrating how virtual peer-to-peer consultations using a secure electronic messaging system can potentially create bridges between often siloed care settings. Systems changes will be necessary in different healthcare environments for VCs to realistically occur. For example, in systems without integrated EHRs or in academic health centers providing consultation for rural or distant primary care physicians, mechanisms for efficient sharing of medical records (including HIPAA compliance) need to be developed. In systems where consultants are paid on a fee-for-service or production model, incentives would need to be provided for consultants to 'accept' virtual consults. However, as EHRs are slowly becoming more common, and data-sharing standards between different EHRs are being developed, we feel that our preliminary findings can inform care integration efforts in different care settings.

Both patient and physician survey respondents are subject to recall bias. Therefore we surveyed patients 
soon after the visit that prompted the consultation order (within 2-4 weeks) and we attempted to partially mitigate this bias among physicians by providing information about the patient so they could reference their chart notes about the visit prompting the consultation request. Patient and physician participation in the surveys was voluntary; therefore, survey respondents may represent a biased sample. We were unable to adjust for differential severity of disease state in patients since to gain sufficient patient numbers we matched on the reason for the consultation using just the first three digits of the ICD-9 code. Therefore, patients with more severe conditions or with multiple co-morbidities may have had a greater need for TC rather than VC.

While we achieved only a modest $30 \%$ physician survey return rate, a more representative $43 \%$ of physicians returned at least one survey. However, our return rates are not inconsistent with other surveys of busy physicians where relatively little incentive (other than continuing medical education credit) was provided [39,40], and the lack of difference in $\mathrm{VC}$ and TC frequencies between responding and non-responding physicians suggests we did not encounter a significant degree of response bias. With a larger sample size (on soliciting patient preference for type of consultation) and a larger response rate (particularly on the application or planned application of knowledge questions) we might have seen additional differences between TCs and VCs. We were not able to capture information on subjective judgments physicians may have made about their patients preferences for referral type. Physician respondents may have been predisposed to rate the consultations highly in order to not rate another department or colleague poorly, and our sample size did not permit comparisons between different specialty departments.

\section{Conclusions}

If additional studies confirm these findings, increased use of VCs may decrease the need for face-to-face specialty encounters without a decrease in the patient's perception in the quality of care, patient or referring physician satisfaction, with a quicker delivery of useful information to physicians requesting consultation. Using VCs for non-urgent consultation requests could potentially improve access to specialty care visits for patients with more urgent problems.

We believe the results of this investigation provide information useful for other specialties and health systems seeking to design virtual consultations to help streamline patient care. The results show the potential for using novel methods of health information technologies to explore new workflows to improve the affordability of health care, provide decision support to clinicians at the point of care, and inform clinicians how to provide alternative forms of medical care. This study also supports the anecdotal findings of the eHealth Initiative demonstration project which concluded EHR communications improved the referral process between primary care and the specialists [31].

Our study is a beginning step in gaining understanding if novel care delivery models can lead to "better, faster, cheaper" processes of care. In future studies we will need to perform a cost/benefit analysis between traditional and virtual consults to evaluate if virtual consults may lead to improved processes of healthcare at lower costs. If the value of the information a physician obtains via a virtual consult is equivalent to that obtained by a traditional consult, but results in saving the patient time (and potentially cost), then it may benefit both the patient and the physician. Therefore a virtual consult may be another way to potentially and conveniently meet patient needs and give physicians another tool for improving their practices.

In future work we plan to include additional incentives to increase percent of surveys returned, examine reasons physicians choose virtual consults for individual patients, assess the consistency of consultation advice with evidence, explore the applicability of our findings to other integrated health care systems as well as systems without electronic medical records or with lesser degrees of EHR implementation, and examine the patient outcomes of virtual consultations.

\section{Additional files}

Additional file 1: Telephone script for introduction and verbal consent for virtual consults patient satisfaction survey.

Additional file 2: Patient satisfaction survey.

Additional file 3: Referring physician Survey.

\section{Abbreviations}

A-CAHPS: Adult ambulatory care consumer assessment of health plans survey; CME: Continuing medical education; CPOE: Computer provider order entry; EHR: Electronic health record; HIPAA: Health insurance portability and accountability act; ICD: International classification of diseases; KPCO: Kaiser Permanente Colorado; KPHC: Kaiser Permanente Health Connect;

PCP: Primary care physician; TC: Traditional consults; VC: Virtual consults.

\section{Competing interests}

TEP and DP are employees of the Colorado Permanente Medical Group. SS and KBW are employees of Kaiser Health Plan Colorado.

\section{Authors' contributions}

TEP carried out the design of the study, assisted in the analysis, and drafted the manuscript. DP participated in the design, assisted in the analysis, and assisted in drafting the manuscript. SS performed all statistical analyses and participated with editing the manuscript. KBW performed the patient and physician surveys and collected data along with editing the manuscript. All authors read and approved the final manuscript.

\section{Authors' information}

TEP is the physician manager for clinical reporting for the Colorado Permanente Medical Group (Denver CO) and a clinician researcher in the Institute for Health Research. He is the chair of the committee for integrating 
new technology with benefits and operations for Kaiser Permanente Colorado. Dr. Palen's research focus is on the use of health information technology for enhancing models of care delivery.

DP is Director of Medical Education for the Colorado Permanente Medical Group (Denver CO) and the Permanente Federation (Oakland CA). He is also co-Director of the Kaiser Permanente Colorado Institute for Health Research's Center for Health Education, Dissemination and Research, and a member of the Board of Directors of the Accreditation Council on Continuing Medical Education. Among Dr. Price's areas of focus are examination of methods of effective physician learning, newer methods of learning for health professionals, and improving the translation of continuing education learnings into practice.

\section{Acknowledgements}

Thanks to Mary Kershner, RN and Jannelle Briggs, RHIT, for conducting chart reviews. Thanks to Dan Winn, BS, for conducting patient surveys. Thanks to Elizabeth Staton and John F. Steiner for reviewing the manuscript and their thoughtful suggestions.

The East Bay Community Foundation provided funding for this study. The funds covered the staff time to conduct the research. Study investigators acted independently and the East Bay Community Foundation was not involved in study design, collection, analysis, or interpretation of the data, nor did they review or approve this manuscript.

This research was approved by Kaiser Permanente Colorado's Institutional Review Board.

All authors had full access to all study data and take full responsibility for the accuracy and integrity of the data presented herein.

Prior presentations: Preliminary results of this work were presented as an abstract at the HMO Research Network, Danville PA, on April 27, 2009.

\section{Author details}

${ }^{1}$ Department of Internal Medicine, Colorado Permanente Medical Group, Institute for Health Research, Kaiser Permanente, Denver, CO, USA. ${ }^{2}$ Department of Education, Colorado Permanente Medical Group, Institute for Health Research, Department of Family Medicine, University of Colorado Denver Health Sciences Center, Denver, CO, USA. Institute for Health Research, Kaiser Health Plan Colorado, Denver, CO, USA. ${ }^{4}$ Knowledge Management and Implementation, Support, Kaiser Health Plan Colorado, Denver, CO, USA.

Received: 16 November 2011 Accepted: 25 June 2012 Published: 8 July 2012

\section{References}

1. DiMatteo MR, DiMatteo MR: Variations in patients' adherence to medical recommendations: a quantitative review of 50 years of research. Medical Care 2004, 42:200-209.

2. Vickery DM, Kalmer H, Lowry D, Constantine M, Wright $E$, Loren W, et al: Effect of a self-care education program on medical visits. JAMA 1983, 250:2952-2956.

3. Hersh W, Miller R, Olson D, Sacherek L, Cross P: Professional's Information Link (PiL): a web-based asynchronous consultation service. In Proceedings AMIA 2002 Symposium: 9-13 September 2002. Edited by Kohane Isaac S. Texas: Hanley and Belfus; 2002:325-329.

4. MacFarlane A, Harrison R, Murray E, Berlin A, Wallace P: A qualitative study of the educational potential of joint teleconsultations at the primarysecondary care interface. J Telemed Telecare 2006, 12(Suppl 1):22-24.

5. Wan AC, Gul Y, Darzi A: Realtime remote consultation in the outpatient clinic-experience at a teaching hospital. J Telemed Telecare 1999, 5(Suppl 5):70-71

6. Umefjord G, Hamberg K, Malker H, Petersson G: The use of an Internet-based Ask the Doctor Service involving family physicians: evaluation by a web survey. Fam Pract 2006, 23:159-166.

7. Umefjord G, Malker H, Olofsson N, Hensjo LO, Petersson G: Primary care physicians' experiences of carrying out consultations on the internet. Inform Prim Care 2004, 12:85-90.

8. Coile RC Jr: "Virtual medicine": the future of American health care. Russ Coiles Health Trends 1999, 11:2-3.

9. Gorman P: Information needs in primary care: a survey of rural and nonrural primary care physicians. Stud Health Technol Inform 2001, $84: 1-42$.
10. Gorman P, Yao P, Shshadri V: Finding the answers in primary care: information seeking by rural and nonrural clnicians. Stud Health Technol Inform 2004, 107(Pt 2):1133-1137.

11. Coumou HC, Meijman FJ: How do primary care physicians seek answers to clinical questions? A literature review. J Med Libr Assoc 2006, 94:55-60.

12. Gonzalez-Gonzalez Al, Dawes M, Sanchez-Mateos J, Riesgo-Fuertes R, Escortell-Mayor E, Sanz-Cuesta T, et al: Information needs and informationseeking behavior of primary care physicians. Ann Fam Med 2007, 5:345-352.

13. Ely JW, Osheroff JA, Chambliss ML, Ebell MH, Rosenbaum ME: Answering physicians' clinical questions: obstacles and potential solutions. J Am Med Inform Assoc 2005, 12:217-224.

14. Bennet N, Casebeer L, Zheng S, Kristofco R: Information-seeking behaviors and reflective practice. J Contin Educ Health Prof 2006, 26:120-127.

15. Covell DG, Uman GC, Manning PR: Information needs in office practice: are they being met? Ann Intern Med 1985, 103:596-599.

16. Ely JW, Osheroff JA, Ebell MH, Bergus GR, Levy BT, Chambliss ML, et al: Analysis of questions asked by family doctors regarding patient care. BMJ 1999, 319:358-361.

17. Ramos K, Linscheid R, Schafer S: Real-time information-seeking behavior of residency physicians. Fam Med 2003, 35:257-260.

18. Osheroff JA, Forsythe DE, Buchanan BG, Bankowitz RA, Blumenfeld BH, Miller RA: Physicians' information needs: analysis of questions posed during clinical teaching. Ann Intern Med 1991, 114:576-581.

19. Angstman KB, Adamson SC, Furst JW, Houston MS, Rohrer JE: Provider satisfaction with virtual specialist consultations in a family medicine department. Health Care Manag 2009, 28:14-18.

20. Howe N, Strauss W: The next 20 years: how customer and workforce attitudes will evolve. Harv Bus Rev 2007, 85:41-52.

21. Shershneva MB, Carnes M, Bakken LL: A model of teaching-learning transactions in generalist-specialist consultations. $J$ Contin Educ Health Prof 2006, 26:222-229.

22. Price D: Point of Care Learning: The Ultimate in Meeting CME Need [education session]. Alliance for Continuing Medical Education Annual Meeting. San Francisco, CA; 2005. http://www.acehp.org/imis15/aCME/PDFs/ Abstracts/05abs.pdf.

23. Bujnowska-Fedak MM, Staniszewski A, Steciwko A, Puchala E, BujnowskaFedak MM, Staniszewski A, et al: System of telemedicine services designed for family doctors' practices. Telemedicine Journal \& E-Health 2000, 6:449-452.

24. Maass MC, Asikainen P, Maenpaa T, Wanne O, Suominen T, Maass MC, et al: Usefulness of a Regional Health Care Information System in primary care: a case study. Comput Methods Programs Biomed 2008, 91:175-181.

25. Moorman PW, Branger PJ, Van der WJ Kam, Van der LJ, Moorman PW, Branger PJ, et al: Electronic messaging between primary and secondary care: a four-year case report. J Am Med Inform Assoc 2001, 8:372-378.

26. Branger PJ, Van't HA, Van der Wouden JC, Moorman PW, Van Bemmel JH, Branger PJ, et al: Shared care for diabetes: supporting communication between primary and secondary care. Int J Med Inform 1999, 53:133-142.

27. Hansagi H, Olsson M, Hussain A, Ohlen G, Hansagi H, Olsson M, et al: Is information sharing between the emergency department and primary care useful to the care of frequent emergency department users? Eur J Emerg Med 2008, 15:34-39.

28. Whited JD, Hall RP, Foy ME, Marbrey LE, Grambow SC, Dudley TK, et al: Teledermatology's impact on time to intervention among referrals to a dermatology consult service. Telemedicine Journal \& E-Health 2002, 8:313-321.

29. Biermann E, Rihl J, Schenker M, Standl E, Biermann E, Rihl J, et al: Semiautomatic generation of medical tele-expert opinion for primary care physician. Methods Inf Med 2003, 42:212-219.

30. Foy R, Hempel S, Rubenstein L, Suttorp M, Seelig M, Shanman R, et al: Meta-analysis: effect of interactive communication between collaborating primary care physicians and specialists. Ann Intern Med 2010, 152:247-258.

31. Centering on the Patient: How Electronic Health Records Enable Care Coordination. eHealth Initiative. Washington, D.C; 2011:1-94. http://www. ehealthinitiative.org/resources/finish/73-general/160-centering-on-thepatient-how-electronic-health-records-enable-care-coordination.html.

32. Adult Ambulatory Care CAHPS survey. 2007. https://www.cahps.ahrq.gov/ quality-improvement/ /media/files/quality\%20improvement/ cahps_amb_pg_041310.pdf. 
33. Ely JW, Osheroff JA, Gorman PN, Ebell MH, Chambliss ML, Pifer EA, et al: A taxonomy of generic clinical questions: classification study. BMJ 2000, 321:429-432.

34. Cummings P, McKnight B: Analysis of matched cohort data. The Stata Journal 2004, 4:274-281.

35. Accreditation Council for Continuing Medical Education Updated Accreditation Criteria. 2009. http://www.accme.org/requirements/accreditationrequirements-cme-providers/accreditation-criteria.

36. Dolcourt JL: Commitment to change: a strategy for promoting educational effectiveness. J Contin Educ Health Prof 2000, 20:156-163.

37. Wakefield JG: Commitment to change: exploring its role in changing physician behavior through continuing education. $J$ Contin Educ Health Prof 2004, 24:197-204.

38. Wakefield JG, Herbert CP, Maclure M, Dormuth C, Wright JM, Legare J, et al: Commitment to change statements can predict actual change in practice. J Contin Educ Health Prof 2003, 23:81-93.

39. Hussainy SY, Beattie J, Nation RL, Dooley MJ, Fleming J, Wein S, et al: Palliative care for patients with cancer: what are the educational needs of community pharmacists? Support Care Cancer 2006, 14:177-184.

40. Price D, Overton C, Duncan J, Wamsley D, Steinbruegge J, Francis L, et al: Results of the first national Kaiser Permanente continuing medical education needs assessment survey. Permanente Journal 2002, 6:76-84.

doi:10.1186/1472-6947-12-65

Cite this article as: Palen et al: Comparing virtual consults to traditional consults using an electronic health record:

an observational case-control study. BMC Medical Informatics and Decision Making 2012 12:65.

\section{Submit your next manuscript to BioMed Central and take full advantage of:}

- Convenient online submission

- Thorough peer review

- No space constraints or color figure charges

- Immediate publication on acceptance

- Inclusion in PubMed, CAS, Scopus and Google Scholar

- Research which is freely available for redistribution 